\title{
Nasal/Oromucosal Spray Solution Dosage Form
}

National Cancer Institute

\section{Source}

National Cancer Institute. NasallOromucosal Spray Solution Dosage Form. NCI

Thesaurus. Code C149693.

Liquid preparation consisting of a solution in a container with or without a metering dose valve or in a container with a spray pump, intended for nasal or oromucosal use. 